\title{
Xylem Vessel Anatomy of Sweet Cherries Grafted onto Dwarfing and Nondwarfing Rootstocks
}

\author{
Mercy A. Olmstead ${ }^{1}$ \\ Department of Horticulture, Washington State University Irrigated Agriculture Research and Extension \\ Center, Prosser, WA 99350 \\ N. Suzanne Lang ${ }^{2}$ \\ Department of Horticulture, Michigan State University, East Lansing, MI 48824
}

Frank W. Ewers ${ }^{3}$

Department of Plant Biology, Michigan State University, East Lansing, MI 48824

\author{
Shirley A. Owens ${ }^{4}$ \\ Center for Advanced Microscopy, Michigan State University, East Lansing, MI 48824
}

\begin{abstract}
Additional index words. Prunus avium, vessel lumen area, vessel hydraulic diameter, confocal laser microscopy, scanning electron microscopy

Abstract. Xylem vessel anatomy was examined in tissues surrounding the graft union of sweet cherry (Prunus avium L.) scion (stem) and nondwarfing, semi-dwarfing, or dwarfing rootstock (root) combinations, to characterize potential changes in anatomical features during the initial stages of graft union formation. Vessel element length, frequency, diameter, lumen area (LAV), and mean vessel hydraulic diameter $\left(V^{2} D_{h}\right)$ were examined in 'Rainier' $(P$. avium) scion wood grafted onto nondwarfing 'Colt' (P. pseudocerasus L. X P. avium) or 'F 12/1' (P. avium) rootstock and semi-dwarfing 'Gisela 6' ['Gi 6' (P. cerasus L. x P. canescens L.)], or dwarfing 'Gisela 5' ['Gi 5' (P. cerasus $x$ P. canescens)] rootstock systems in: heterograft combinations (commercial scion-rootstock combinations); homografts (scion and rootstock are the same genetic material); and reciprocal heterografts (rootstock tissue grafted onto scion tissue). Vessel element length was not affected by rootstock, but vessel frequency and lumen area in graft union tissues were smaller in 'Rainier'/' Gi 5' (dwarfing combination) than in 'Rainier'/“Colt'(nondwarfing combination). The heterograft combination of 'Rainier'/'Gi 5 ' had smaller scion LAV, lower $\mathrm{VD}_{\mathrm{h}}$ and narrower vessels than homograft or reciprocal heterograft combinations. As callus differentiated into vascular elements, xylem rays in 'Rainer'/'Gi 5' tended to develop at an acute angle to the longitudinal axis of the tree and there was an increase in nonfunctional phloem in 'Rainer'/'Gi 5' compared to 'Rainer'/'F 12/1'. Collectively, the data provides further evidence that a combination of smaller and fewer vessels in the scion and graft union, as well as irregular vessel orientations in the vascular tissue within dwarfing combinations could contribute to hydraulic resistance in the graft union resulting in reduced scion growth (dwarfing).
\end{abstract}

Successful graft unions result when cells at the surface of both scion (stem) and rootstock (root) tissue complete the sequence of wound response (callus proliferation and differentiation), to creation of a continuous cambium and vascular system between scion and rootstock. As a method of plant propagation, grafting has been used for centuries to impart a change in disease resistance, size (dwarfing), form and/or growth habit on the scion. Several hypotheses have been proposed to explain reduced scion growth, or dwarfing effects of some rootstocks, including alterations in concentrations or ratios of plant hormones (Jones, 1986; Kamboj et al., 1997, 1999; Sommelidou et al., 1994a); partial genetic incompatibility of rootstocks and scions (Gur et al., 1968); necrosis in the graft union (Gur et al., 1968); and decreased hydraulic conductivity between rootstock and scion as a result of vascular anomalies (Gur and Blum, 1975). However, there appears to be no single mechanism or unifying hypothesis for the observed

Received for publication 29 Nov. 2005. Accepted for publication 30 Apr. 2006. The authors would like to thank Dr. J. Tarara and Dr. J. Olmstead for their suggestions on this manuscript.

${ }^{1}$ Former Graduate Student, current Assistant Professor. To whom reprint requests should be addressed. E-mail: molmstead@wsu.edu, Fax: 509-786-9370.

${ }^{2}$ Associate Professor.

${ }^{3}$ Professor.

${ }^{4}$ Academic Specialist. alteration in tree size. In apples (Malus domestica Borkh.), differences in the growth of individual cellular components in the vascular systems of dwarfing and vigorous (nondwarfing) root systems have been attributed to alterations in the differentiation of wound tissue. For example, a lower proportion of xylem vessels to phloem cells (Beakbane and Thompson, 1939, 1947) and smaller vessel elements (Beakbane and Thompson, 1939, 1947; McKenzie, 1961) occur in roots of dwarfing versus vigorous apple rootstocks. Such differences in root vascular anatomy can play a major role in tree growth and productivity because they regulate the rate of transport in the plant (Jones, 1974), which is based largely upon the amount of functional xylem and the frequency and diameter of vessels in the wood (Tyree and Ewers, 1991).

Additionally, there may be inherent differences in water transport between nongrafted and grafted plants due to the success of callus differentiation yielding a contiguous connection in the vascular system. It was hypothesized that number and size of functional xylem elements can decrease during differentiation of callus tissue to vascular tissue, leading to lower hydraulic conductance, especially in grafted combinations that utilize dwarfing rootstocks (Atkinson et al., 2001, 2003). Hydraulic conductivity, the ratio of water flow to its known driving force, can indicate the rate of water movement through stem or branch tissue. This is illustrated by ungrafted apple rootstocks, in which root hydraulic conductivity was lower in the dwarfing ['Malling 27' 
('M.27')] than in the semi-vigorous rootstock ['Malling-Merton 106' ('MM.106')] (Atkinson et al., 2003). Similar differences in conductivity were observed in stem sections and leaves, suggesting that reduced hydraulic conduction and hence water transport in dwarfing tissues may be limited inherently by both size and/or number of functional vessel elements. It has been suggested that when dwarfing rootstocks are used to control scion growth, low hydraulic conductance in the graft union may be a barrier to meeting the transpiration demands of certain leaf areas, in addition to the root system's potentially diminished ability for water absorption (Basile et al., 2003).

Within a graft union, the development and differentiation of vascular tissue varies with scion-rootstock combinations (Jones, 1974; McKenzie, 1961; Simons and Chu, 1980). Smaller vessel diameters in the graft union of scions grafted onto dwarfing apple rootstocks occur, reducing water transport and overall hydraulic conductivity within and between grafted tissues (Poniedzialek et al., 1979). Additionally, smaller vessel diameters can alter the auxin : cytokinin ratio (Soumelidou et al., 1994a, 1994b), which affects callus differentiation of xylem and phloem in the graft union.

Further, disorganization of developing vascular tissues in the graft union region could affect water transport. Structural anomalies in vascular element anatomy initiated during graft union healing can independently, but profoundly restrict transport of water, nutrients, plant hormones, and/or photoassimilates (Atkinson et al., 2003; Gur and Blum, 1975; Sommelidou et al., 1994a). These anomalies include the excess production of parenchyma cells, excess production of nonfunctioning phloem, and production of xylem rays on an acute angle to the longitudinal axis of the tree. Restriction of xylem transport may also occur due to misalignment of vascular tissues with dwarfing rootstock combinations (Simons and Chu, 1980). Collectively, previous research suggests there could be a significant increase in hydraulic resistance in the graft union of dwarfing rootstock due to multiple physical restrictions. Unfortunately, even with the substantial body of evidence for restriction of water transport in grafted systems, vessel differentiation and development within the initial stages of graft wound healing have not been characterized and are not well understood in a group of dwarfing cherry rootstock combinations used internationally for over 10 years. The structural interface between scion and rootstock may in fact be a key to limitations in the flow of not only water, but also signals which control the developmental changes essential to successful scion-rootstock growth which results in dwarfing scion growth.

The objectives of this research were to determine whether vessel anatomy in the initial stages of graft union formation in dwarfing rootstock combinations in sweet cherry could contribute to reductions in water movement through the graft union, leading to reduced growth of the scion (i.e., dwarfing). The hypothesis that grafting influences the hydraulic architecture of the scion, graft union and/or rootstock due to limitations from both wounding, and the subsequent interface between genetically different scion and rootstocks of diverse growth potential (vigor) was tested. Current plant micro-technique was used to anatomically determine vascular attributes (size and number) of functional vessels in ungrafted nondwarfing, semi-dwarfing, and dwarfing rootstocks as compared to intraspecific homografts (bud tissue grafted to genetically identical rootstock tissue), interspecific heterografts (commercial scion-rootstock combinations), and interspecific reciprocal heterografts (inverted scion-rootstock combinations).

\section{Materials and Methods}

In Mar. 2001, 36 'Rainier' sweet cherry trees grafted onto three commercially clonally propagated rootstocks were planted in $8.8-\mathrm{L}$ pots and placed in a lathe house at the Horticulture Teaching and Research Center (HTRC) at Michigan State Univ., East Lansing. 'Rainier' was selected to minimize variation due to differences in genetic material, especially with the availability of ' $F 12 / 1$ '. The three cherry rootstocks were classified by their dwarfing effects: dwarfing ('Gi 5'), semi-dwarfing ('Gi 6'), and nondwarfing ('Colt'). 'Colt' rootstocks were used as a nondwarfing rootstock due to the limited availability of ' $\mathrm{F} 12 / 1$ ' rootstock in the United States, for the 2001 growing season. Additionally, 'Colt' was selected because it is a common rootstock widely planted in different cherry growing areas worldwide. All plant materials were obtained from commercial suppliers, certified to be "free of detectable pathogens." Ungrafted rootstocks were used as nonwounded controls (Table 1). To determine the effect of genetically different rootstocks on scion vascular differentiation, intraspecific homografts (scion tissue grafted onto genetically identical rootstock) and interspecific heterografts (commercial scion-rootstock combinations) were constructed in Aug. 2001. Homograft combinations were included in the experiment to differentiate the wounding effect of grafting, from the response of grafting genetically different scion-rootstock combinations (Table 1). For heterografts, each of the three rootstocks was chip-budded (a small piece of rootstock tissue was removed above the "rootshank" and a single scion bud was then placed in contact with the rootstock cambium at that location) with the sweet cherry scion 'Rainier.' Trees were moved into a greenhouse in September to prolong growth of the developing graft union. Day/night temperatures were $24 / 10^{\circ} \mathrm{C}$ and supplemental lighting $\left[\approx 1750 \mu \mathrm{mol} \cdot \mathrm{m}^{-2} \cdot \mathrm{s}^{-1}\right.$ photosynthetic photon flux density $\left.(P P F D)\right]$ was supplied with high pressure sodium lamps to achieve a $14 \mathrm{~h}$ day/10 h night regimen.

In Apr. 2002, 225 rootstocks each of ' $\mathrm{Gi}$ 5', ' Gi 6', and 300 'F $12 / 1$ ' were planted into $13.2-\mathrm{L}$ pots and placed in a greenhouse with maximum temperatures of $25^{\circ} \mathrm{C}$ and ambient irradiance (maximum $\left.\approx 1385 \mu \mathrm{mol} \cdot \mathrm{m}^{-2} \cdot \mathrm{s}^{-1} P P F D\right)$. After 1 month of growth, trees remained ungrafted (controls) or were chip-budded to create seven different combinations representing heterografts, reciprocal heterografts, and homografts to examine the effect of different genetic material on vascular development at the graft union (Table 1). The combination 'Rainier'/'F 12/1', consisting of two different clones of $P$. avium, was utilized as both a homograft $(P$. avium/P. avium) and a heterograft ('Rainer' scion/nondwarfing rootstock) due to the unavailability of both ' $F$ 12/1' budwood and/or own-rooted 'Rainier.'

CONFOCAL LASER SCANNING MICROSCOPIC (CLSM) ANALYSIS OF 2001 TREES. To determine the developmental changes in xylem anatomy in the first 6 months after grafting, sections from each scion-rootstock combination were collected monthly. Images were collected and analyzed for average vessel length, diameter, hydraulic diameter, and lumen area per vessel using Sigma Scan Pro 5.0 (Systat Software, Richmond, Calif.) as described below. Total tissue removed from each individual plant consisted of 2-cm-long transverse segments of scion $(\approx 15 \mathrm{~cm}$ above soil level), graft union (10-13 cm above soil level), and rootstock tissue ( $\approx 8-10 \mathrm{~cm}$ above soil level). Ungrafted rootstock samples were collected simultaneously at the approximate height on the tree as the samples from grafted trees (beginning $\approx 8 \mathrm{~cm}$ above soil level). Upon removal from the growing trees, samples were 
Table 1. Graft combinations for vascular anatomy studies of dwarfing and vigorous rootstocks with 'Rainier' sweet cherry scion. Intraspecific homografts consisted of bud tissue grafted onto genetically similar tissue, interspecific heterografts consisted of traditional scion-rootstock trees, and interspecific reciprocal heterografts consisted of inverted scion-rootstock trees. Rootstocks included were 'Gisela 5' (Gi 5), 'Gisela 6' (Gi 6), 'Colt', and 'F 12/1'.

\begin{tabular}{lcc}
\hline Year & & Graft combinations \\
\hline 2001 & Controls & Gi 5, Gi 6, and Colt ungrafted trees \\
& Intraspecific homografts & Gi 5/Gi 5, Gi 6/Gi 6, and Colt/Colt \\
& Interspecific heterografts & Rainier/Gi 5, Rainier/Gi 6, and Rainier/Colt \\
\hline 2002 & Controls & Gi 5, Gi 6, and F 12/1 ungrafted trees \\
& Intraspecific homografts & Gi 5/Gi 5, Gi 6/Gi 6, and Rainier/F 12/1 \\
& Interspecific heterografts & Rainier/Gi 5, Rainier/Gi 6, and Rainier/F 12/1 \\
& Interspecific reciprocal heterograft & Gi 5/F 12/1, Gi 6/F 12/1 \\
\hline
\end{tabular}

placed directly into a formalin-acetic acid-alcohol solution (10 formalin : 5 acetic acid : 50 ethanol solution) (Ruzin, 1999) and immersed for 1 week, after which the solution was changed to 50 ethanol : 50 water for storage until sectioning at room temperature. Longitudinal sections ( $3 \mathrm{~cm}$ long, $20 \mu \mathrm{m}$ thick) were made with a sliding microtome, placed on glass slides, and rehydrated with distilled water prior to staining. For transverse sections the tissue was embedded in a water-soluble wax (Carbowax 1500; Dow Chemical Co., Midland, Mich.), sectioned (15 $\mu \mathrm{m})$ with a rotary microtome, and placed in an oven for $6 \mathrm{~h}$ at $55^{\circ} \mathrm{C}$ to flatten and remove the wax from sections (Steedman, 1960).

Sections were stained with Safranin O, a fluorescent dye that excites with blue light $(\approx 530 \mathrm{~nm})$ and emits in the yellow range ( $>520 \mathrm{~nm}$; Lillie, 1977). Fluorescent images were obtained using a 488-nm argon laser line for excitation and a 520-nm-long pass filter for emission. Unstained samples of the same tissue were observed using the same microscopic parameters to ensure that the fluorescence signal was not from autofluorescence. Preliminary analyses indicated that vessel anatomy was uniform within each of the three separate tissue locations, so results of section examination is based on the following three physical locations: scion, graft union and rootstock. Images of unstained and stained samples were captured using a CLSM (40× dry, Zeiss 210; Carl Zeiss, Jena, Germany) with digital image storage capability. Callus cells in the developing scion-rootstock union were monitored and mature vessels were measured as they developed.

SCANNING ELECTRON MICROSCOPIC (SEM) ANALYSIS OF 2002 TREES. Initial sampling of vessel diameters was done with CLSM in 2001. However, the SEM method was deemed more practical for processing the large number of samples and accumulating the large data sets within the 2002 experiment, thus the SEM method was used for the analysis of all samples harvested in 2002. Images were collected and analyzed for average vessel length, diameter, hydraulic diameter, and lumen area per vessel using Sigma Scan Pro 5.0 as described below. Tissues from ungrafted trees and all grafted combinations were harvested monthly for 6 months after bud-grafting. Samples were then divided into the three physical locations (scion, graft union, and rootstock) for sectioning, fixed, and stored as described for CLSM analysis in the 2001 experiment. At 6 months after grafting, samples were sectioned into transverse and longitudinal sections $(120 \mu \mathrm{m})$ with a sliding microtome, and placed into $2-\mathrm{mL}$ microcentrifuge tubes for dehydration in preparation for SEM. Sections were dehydrated in a graded ethanol series and critical point dried in liquid $\mathrm{CO}_{2}$ (Flegler et al., 1993). To further facilitate drying, samples were kept in desiccators at ambient temperature for one week before being coated with gold and examined. Images were captured with a scanning electron microscope (JEOL JSM-6400V; JEOL,
Peabody, Mass.) and the analySIS program (Soft Imaging System $\mathrm{GmbH}$, Lakewood, Colo.) to capture images for measurement of vessel number $(\times 100)$ and vessel lumen area $(\times 150)$ within current year growth.

IMAGE ANALYSIS. Composite images of 2002 samples were constructed using Adobe Photoshop 6.0 (Adobe Systems, San Jose, Calif.) by layering images and matching overlapping features to construct a continuous cross-sectional image from pith to bark. All images were then analyzed using the trace measurement tool in Sigma Scan Pro 5.0. The image was calibrated to a defined dimension, and desired image features (vessel/lumen size) were measured. The trace measurement tool, within Sigma Scan Pro allows the user to define, within a specific scale, two points on an image and measure the feature. Using this method, vessel cell differentiation and development were followed during the first 6 months of graft wound healing. Vessel measurements were restricted to the same cell lineage (i.e., growth ring) in 2002. By restricting measurements to mature vessels (primary xylem), vessels that were expected to have the highest hydraulic conductance and thus greatest importance to transport were included (Zimmerman and Jeje, 1981).

For both CLSM and SEM analysis, vessel diameter (VD) was computed from the mean of two measurements perpendicular to each other across the widest part of the lumen for each vessel. Average LAV was calculated from the two measured diameters for each vessel, assuming an elliptical lumen. Total number of vessels measured varied according to each treatment. Vessel frequency per unit cross-sectional area (square millimeters) was determined manually from 2001 images (field of view equaled $534.2 \mu \mathrm{m}^{2}$ at 10x), with only earlywood vessels used to determine vessel frequency. Vessel element length was delineated by the perforation plate of each vessel element and determined from CLSM images. In 2002, vessel frequency was counted from the pith to vascular cambium of each section and vessel frequency included both late- and earlywood within the annual growth ring.

Vessel hydraulic diameter (Pockman and Sperry, 2000) was calculated to indicate potential water transport. By HagenPoiseuille's Law, the rate of fluid flow through a cylinder is proportional to the fourth power of the cylinder's radius (Nobel, 1999; Tyree and Zimmerman, 2002). Thus, large vessels transport proportionately more xylem sap per unit radius than do narrow vessels, providing all other variables are constant. Reporting only the mean measured diameter of xylem vessels thereby underestimates the contribution of larger vessels to the overall hydraulic conductivity of the stem, due to differences in distribution of both wide and narrow vessels. For this reason, it is useful to compute distributions of vessel diameters that have been weighted to account for their contributions to xylem flow 
(i.e., $\mathrm{VD}^{4}$ ). These vessels account for $95 \%$ of the xylem flow in a stem. The mean of this "hydraulically weighted" distribution is given by $\Sigma \mathrm{d}^{5} / \Sigma \mathrm{d}^{4}$ (Pockman and Sperry, 2000) and is referred to as the "hydraulic mean." In this paper, we refer to this value for each tree or tissue location as the $\mathrm{VD}_{\mathrm{h}}$.

STATISTICAL ANALYSIS. Each experiment was arranged in a split plot, completely randomized design, with rootstock type as the main treatment, and tissue type as the sub-plot treatment. Failed bud unions were not included. General linear models (GLM) were used as appropriate, with alpha levels set at 0.05 , a priori. Data were assumed to be normal and continuous with homogeneous variances. When normality was not satisfied, data were transformed logarithmically to gain normality before statistical analysis. Mean separation was accomplished using Tukey's honestly significant difference (HSD) and Fisher's least significant difference (LSD) as appropriate (SAS Institute, Cary, N.C.).

\section{Results}

Average lumen area per vessel. For 2001, vessel element differentiations were observed in each of the ungrafted rootstocks, with LAV fluctuating significantly for all rootstocks over the 6 months of sampling (Fig. 1A). This was most likely caused by vessel maturation and cell differentiation in the area examined within that time period, which displaced older cells to the inner portions of the stem. These data show how immature vessel elements (secondary xylem) fluctuated in mean cell diameter and lumen area. However, by months 5 and 6 when cell maturation was more advanced, ungrafted 'Gi 5' (dwarfing rootstock) had significantly smaller vessels than ' Gi 6' (semi-dwarfing rootstock) or 'Colt' (nondwarfing rootstock) (Fig. 1A). Differences in LAV between ungrafted ' $G i 5$ ' and 'Colt' are visible in CLSM images, with numerous smaller vessels in 'Gi 5' (Fig. 2B).

Callus cells rapidly proliferated in the graft union of heterografts and homografts during the first 2 months after bud grafting and vessel differentiation occurred between 2 and 3 months after grafting (data not shown). In homografts (Fig. 1B), LAV was significantly greater for both of the Gisela rootstocks in the first month after grafting (ranging from 1500 to $>2500 \mu \mathrm{m}^{2}$ ) than ungrafted Gisela rootstocks $\left(\approx 800 \mu \mathrm{m}^{2}\right.$, Fig. 1A) or heterograft $(1000-1200$ $\mu \mathrm{m}^{2}$, Fig. 1C) combinations. In heterografts, 'Rainier'/'Gi 5' combination had the lowest LAV in the graft union from 4 to 6 months after grafting (Fig. 1C). Although these differences were statistically significant for the $2001 \mathrm{LAV}$ data, it may be difficult to separate wounding or rootstock influences from the impact of the semi-ring porous architecture of Prunus L., which produces differences in LAV over time, with larger vessels produced early in the growing season (earlywood) followed by smaller vessels later in the growing season (latewood).

In 2002, LAV for ungrafted rootstocks increased with rootstock expected vigor (i.e., 'Gi 5'< 'Gi 6'< 'F 12/1') and in general ungrafted rootstocks had larger vessel elements than grafted tissues (Fig. 3A). The 'Rainer'/'Gi 6' graft combination had little callus formation and cell differentiation in the graft union, with the majority of scion buds failing to grow (Fig. 3A). Among grafted trees that did form successful graft unions, the commercial graft combination of 'Rainer'/'Gi 5' had the smallest vessel elements in scion, graft union and rootstock tissues in comparison to all other combinations. An SEM image of graft union tissue in 'Rainier'/'Gi 5 'illustrates that in addition to smaller vessels, tissue growth occurred at acute angles in the graft union (Fig. 4D). These anomalies were exclusive to this heterograft combination.

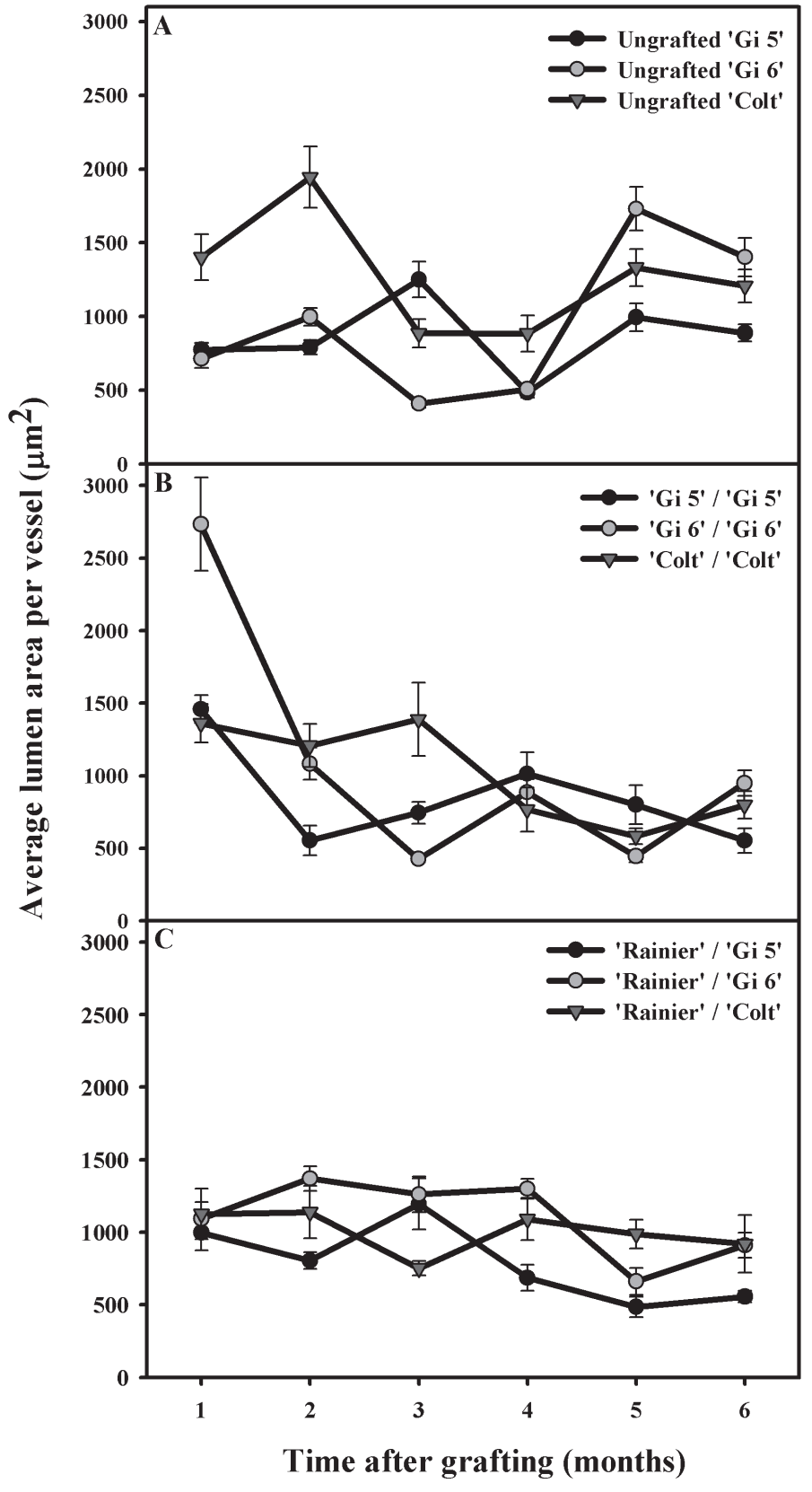

Fig. 1. Lumen area of individual vessel elements as measured from confocal laser microscopy images in 2001 from sweet cherry scion-rootstock combinations. Ungrafted rootstocks were used as controls (A), and sampling locations were harvested at the approximate height on the tree as the corresponding sample from grafted combinations. Graft union sections of grafted combinations are presented for homografts (B) and heterografts $(\mathbf{C})$. Sampling commenced 1 month after bud-grafting. Rootstocks included were 'Gisela 5' ('Gi 5'), 'Gisela 6' ('Gi 6'), and 'Colt', with 'Rainier' sweet cherry as scion tissue in heterograft combinations. Error bars denote one SE $(n=3)$.

When reciprocal graft combinations are examined, ' $\mathrm{Gi} 6$ ' $/{ }^{\circ} \mathrm{F}$ $12 / 1$ ' had significantly greater scion LAV than in ' $\mathrm{Gi}$ ' '/' $\mathrm{F} 12 / 1$ ' (Fig. 3A). Additionally, scion LAV was greater for both Gisela ('Gi 5' and 'Gi 6') reciprocal treatments, than their respective homografts or scion tissue of the 'Rainier'/'F 12/1' combination. Thus, the Gisela rootstocks may in fact have different cell differentiation characteristics when used as scion vs. rootstock tissue. 

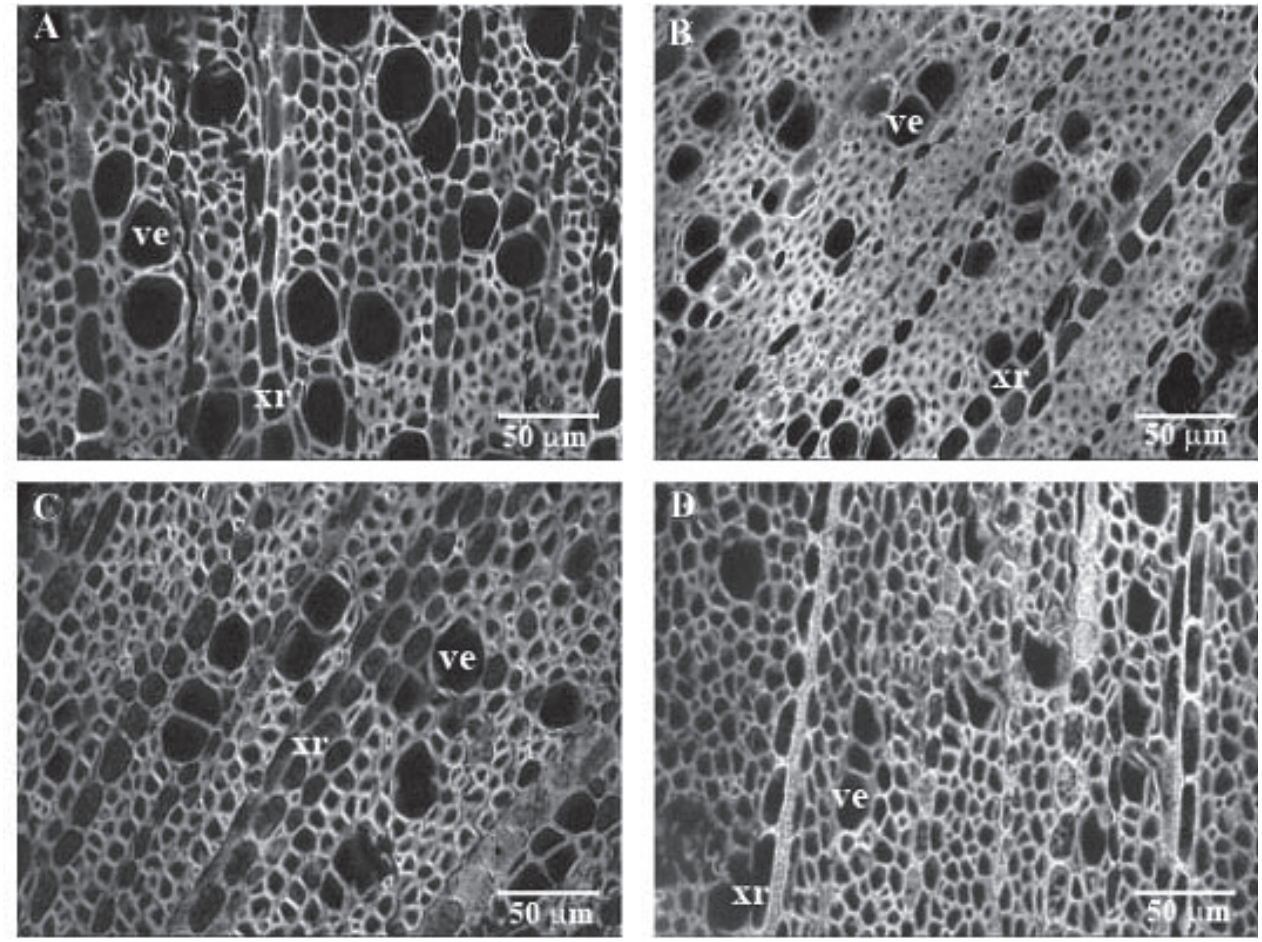

Fig. 2. Fluorescence images captured using confocal laser microscopy of vessels in ungrafted sweet cherry rootstocks of 'Colt' (A) and 'Gisela 5' (B); and in central graft union sections of 'Rainier'/'Colt' (C) and 'Rainier'/'Gisela 5' (D) in 2001. All images are of tissue 6 months after bud-grafting. Sections of ungrafted rootstock were taken at the approximate height as in grafted combinations. In images $(\mathrm{A}-\mathrm{D}), \mathrm{ve}=$ vessel element, $\mathrm{xr}=$ xylem ray.

VESSEL FREQUENCY. In 2001, vessel frequency was reduced in grafted tissue as compared to ungrafted rootstocks. All ungrafted rootstocks had more vessels than their respective grafted combinations (Table 2). In grafted trees, vessel frequency did not vary in the same pattern as LAV. Among scion, graft union, and rootstock tissues of homograft treatments (i.e., genetically identical grafted material), 'Gi 6'/'Gi 6' had the most vessels in its graft union, although 'Gi 5'/'Gi 5' did not statistically differ from 'Gi 6 '/'Gi 6' or 'Colt'/'Colt' (Table 2). For heterograft combinations 'Rainier'/'Colt' tended to have lower vessel frequency in graft union tissues than in graft union tissues of 'Rainier'/'Gi 5', with 'Rainier'/'Gi 6' intermediate in vessel frequency. There were no significant differences in vessel element length among ungrafted trees, homografts, or heterografts.

In 2002, vessel frequency in ungrafted rootstocks was significantly higher than in all grafted combinations, with 'Gi 6' having the highest vessel frequency, followed by 'Gi 5 ' and' $F$ 12/1', which were the same (Fig. 3B). In 'Rainier'/'Gi 5', there was a significant, progressive reduction in vessel frequency from the rootstock to the graft union with a further decrease in scion tissues.

VESSEL HYDRAULIC DIAMETER AND MAXIMUM VESSEL DIAMETER. The maximum vessel diameter $\left(\mathrm{VD}_{\max }\right)$ and $\mathrm{VD}_{\mathrm{h}}$ both support the hypothesis that wound-related callus formed as a result of grafting does not differentiate vessels to their maximum potential. In general, ungrafted ' $\mathrm{Gi}$ 5', 'Gi 6', and 'Colt' rootstocks had greater $\mathrm{VD}_{\mathrm{h}}$ than their respective homo- or heterograft combinations (Table 3 ), supporting the possibility that callus tissues formed during the wound-related callus formation do not differentiate vessels to their maximum potential. Further evidence of the impact of woundrelated callus formation is found by examining vessel frequency for both ungrafted and grafted combinations (Table 2). There was a significant difference in vessel frequency between the different rootstocks when they are not wounded, with ungrafted 'Gi 6' having a greater number (Table 2 ) of smaller vessels (Table 3 ) than ungrafted 'Colt'. However, when wound-related callus formation occurred, the mean vessel frequency for all combinations dropped to the number found in ungrafted 'Colt' rootstocks.

Yet wound-related callus formation does not appear to be the only factor that impacts subsequent vessel element size. It is ' $\mathrm{Gi}$ 5', with the greatest potential to reduce scion growth, which had smaller $\mathrm{VD}_{\max }$ and $\mathrm{VD}_{\mathrm{h}}$ than ungrafted 'Gi 6' or 'Colt' rootstocks. 'Rainer'/'Gi 5' had substantially smaller $\mathrm{VD}_{\max }$ for scion and $\mathrm{VD}_{\mathrm{h}}$ for graft union tissues, in comparison to grafted combinations containing 'Gi 6' and 'Colt'.

$\mathrm{VD}_{\mathrm{h}}$ values in 2002 were significantly different among ungrafted rootstocks, with ' Gi 5' (dwarfing rootstock) intermediate between the nondwarfing 'F 12/1' and semi-dwarfing ' $\mathrm{Gi} 6$ ' rootstocks (Table 4). 'F 12/1' rootstocks had $\mathrm{VD}_{\mathrm{h}}$ values that were the largest for ungrafted rootstocks, the rootstock tissues of the homograft combination 'Rainer'/'F 12/1', as well as the reciprocal heterograft combinations of ' $\mathrm{Gi} 5$ '/' $\mathrm{F} 12 / 1$,' and 'Gi 6'/'F 12/1' (Table 4). 'Rainier'/'Gi 5' had the smallest scion $\mathrm{VD}_{\mathrm{h}}$ in addition to a $77 \%$ reduction in $\mathrm{VD}_{\mathrm{h}}$ between graft union and scion tissues that were not observed in any other graft combination.

VASCULAR ANOMALIES. SEM micrographs revealed that as might be expected; ungrafted ' $\mathrm{F} 12 / 1$ ' (Fig. 4A) had a larger radius from pith to bark at the trunk height of a hypothetical graft union than ungrafted 'Gi 5' (Fig. 4B). When these two rootstocks were grafted with 'Rainier,' callus production and cell differentiation increased the radius in both 'Rainier'/“F 12/1' (Fig. 4C) and 'Rainier'/'Gi $5^{\prime}$ ' Fig. 4D). There was an increase in nonfunctional phloem between ungrafted and grafted trees. When 'Gi 5' was used as a rootstock, there was a $64 \%$ increase in nonfunctional phloem in 'Rainier'/'Gi 5' compared to 'Rainier'/'F 12/1' (Fig. 4C-D). As callus tissue differentiated into vascular elements, xylem rays in 'Rainier'/'Gi 5' tended to develop nonlinearly compared with the linear development of xylem rays in 'Rainier'/'F 12/1' (Fig. 4C-D). Within the graft union of 'Rainier'/'Gi 5,' callus tissue in this region developed vascular anomalies that were evident upon higher magnification (Fig. 5), such as xylem vessels that developed at an acute angle to the longitudinal axis of the tree. Whorls of xylem vessels were also present in grafted tissue of 'Rainier'/'Gi 5' that were not present in other ungrafted tissue or combinations.

\section{Discussion}

The focus of this work was to test the hypothesis that grafting influences the hydraulic architecture of the scion, graft union, 


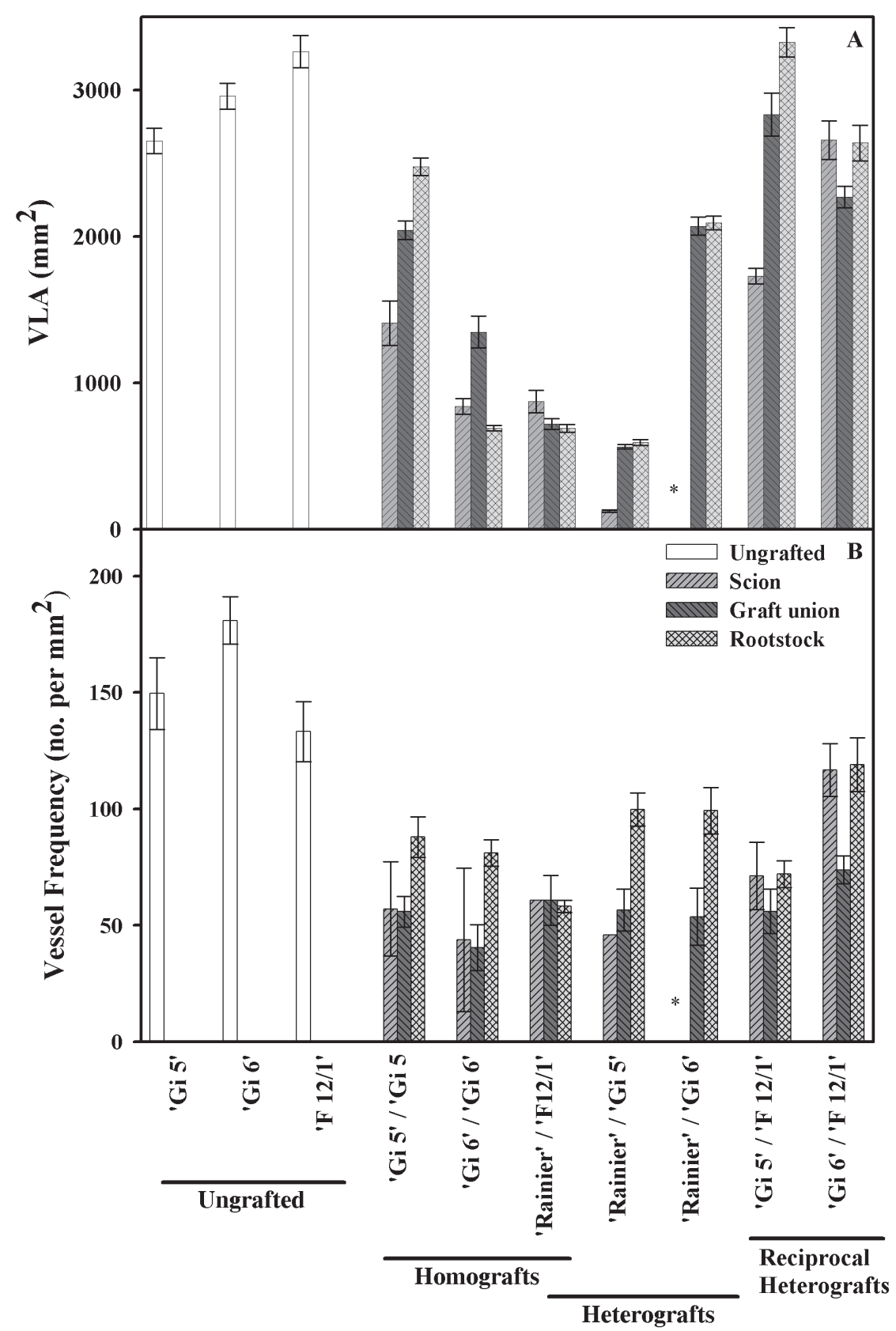

Fig. 3. Average lumen area per vessel (LAV) (A) as determined in mature vascular tissue in sweet cherry scion-rootstock combinations at 6 months after bud-grafting in 2002, and vessel frequency per $\mathrm{mm}^{2}(\mathbf{B})$ as determined by measurement of the entire diameter from pith to outer bark. Ungrafted rootstocks were used as controls, and samples were taken at the approximate height as in grafted combinations. For grafted treatments, scion tissue is indicated first, followed by the rootstock identification. Rootstocks included were 'Gisela

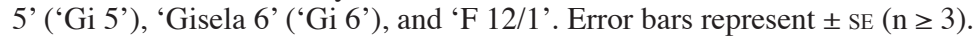

and/or rootstock as a result of wound-related callus formation response and the subsequent interface between scion and rootstock tissues. Vessel element size ( $\mathrm{LAV}$ and $\mathrm{V}_{\text {max }}$ ) as well as vessel hydraulic diameter $\left(\mathrm{VD}_{\mathrm{h}}\right)$ differed by rootstock dwarfing potential, with ' $G i$ ' 5 ' generally having smaller vessel elements. This was verified by CLSM, giving visible evidence that ungrafted ' $G i$ ' had a significantly greater number of smaller vessel elements than 'Colt' and ' $F$ 12/1'. Although the total number of vessel elements was reduced in all grafted combinations, the relationship of a proportionally greater number of smaller vessel elements in ' $\mathrm{Gi}$
5' was maintained relative to 'Colt'. This suggests with 'Gi 5', callus generation and vessel differentiation may lead to reduced vessel size in scion and graft union tissues.

The same relationship between ungrafted and grafted rootstocks was found when ' $\mathrm{Gi}$ 5' and 'Gi 6' rootstocks were compared to nondwarfing ' $F$ 12/1' rootstock. LAV of ungrafted rootstocks decreased with increasing dwarfing potential (i.e., $\mathrm{LAV}=$ 'F 12/1' > 'Gi 6' > 'Gi 5 '). Also, the nondwarfing rootstock had the greatest $\mathrm{VD}_{\mathrm{h}}$ values and a greater radius from pith to bark than the rootstock with the greatest dwarfing potential.

Not only were the inherent vascular differences between rootstocks apparent, but also the impact of wound-relate callus formation due to grafting, was clearly evident in the present work. This effect was apparent in the reduction of vessel size and total vessel number from ungrafted to grafted rootstocks; $\mathrm{VD}_{\max }$ of ungrafted rootstocks were greater than graft union sections of their respective homografts and heterografts. In most cases ungrafted rootstocks had greater vessel frequency than grafted combinations. Thus, the potential growth and development of the vascular system was not reached even after 6 months of wound healing.

An overall effect of wound-related callus formation on $\mathrm{VD}_{\mathrm{h}}$ was observed in scion tissue which had consistently lower $\mathrm{VD}_{\mathrm{h}}$ than graft union tissue. There was a significant decrease in vessel frequency between graft union and scion tissue of combinations with ' $\mathrm{Gi}$ 5' or ' $\mathrm{Gi}$ 6 ' as the rootstock. However, in two of the three grafted combinations containing ' $\mathrm{F} 12 / 1$ ' as the rootstock, there were no significant differences in vessel frequency between graft union and scion tissue. This suggests an impact from the nondwarfing rootstock on scion growth that influenced vessel differentiation.

The decrease in LAV of the 'Rainier'/' $\mathrm{Gi}$ 5 ' graft union during the last 3 months of the experiment was especially significant because this region is an area of major hydraulic resistance. The $\mathrm{VD}_{h}$ data suggest scion tissues of heterografts utilizing a dwarfing rootstock may have lower water flux through the tissue than in homografts. Also, the $\mathrm{VD}_{\mathrm{h}}$ tended to be lowest in grafted combinations containing ' $\mathrm{Gi}$ 5 ' as a rootstock, implying decreased potential for water and nutrient movement through the graft union and scion on ' $\mathrm{Gi} 5$ ' rootstocks. Thus, the resulting vascular differentiations are changed in a way to significantly alter vascular architecture so that transport could be altered in a heterograft combination. Other grafted treatments (heterograft and homograft) showed a slight increase or stable $\mathrm{VD}_{\mathrm{h}}$ values throughout the graft union region, suggesting little change in the resistance of the pathway from rootstock to scion. This supports the hypothesis that hydraulic resistances are increased at the graft union of dwarfing systems (Atkinson et al., 2003). 

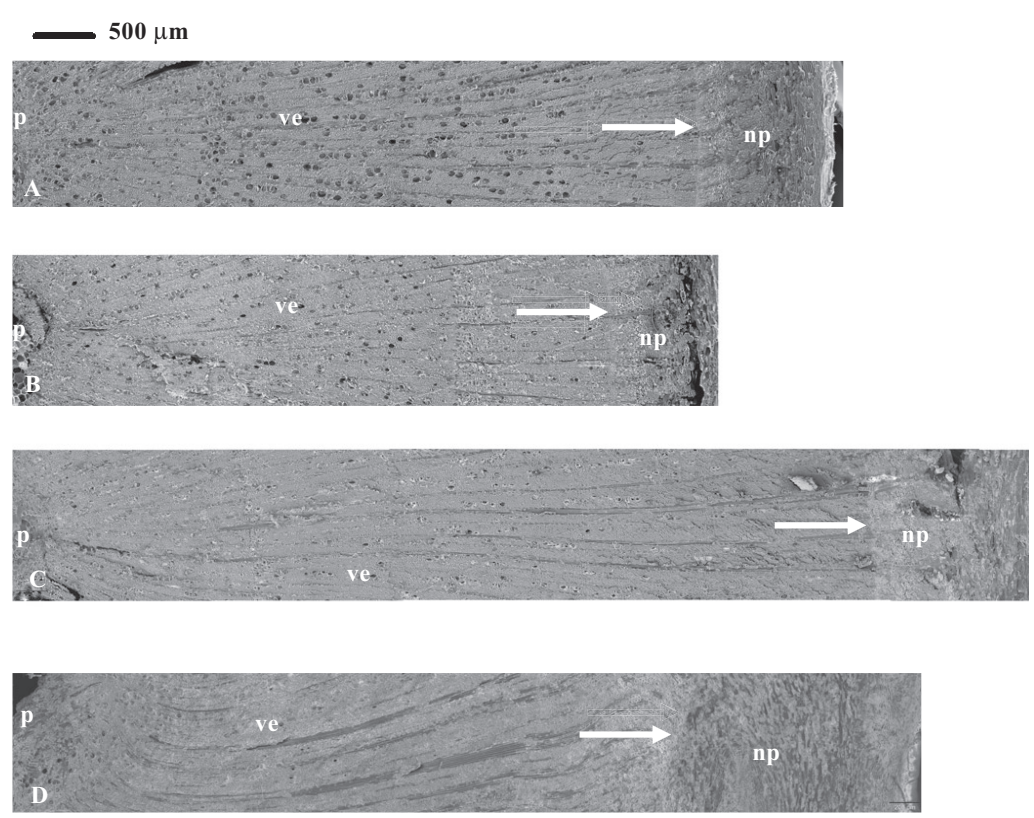

Fig. 4. Composite SEM images of trunk sections in ungrafted ' $F 12 / 1$ ' (A) and 'Gisela 5' (B) sweet cherry rootstocks, and in graft union tissues of 'Rainier'/‘ $\mathrm{F}$ $12 / 1$ ' (C), and 'Rainier'/'Gisela 5' (D) sweet cherry grafted trees. Arrows indicate the vascular cambium in each image. In all images, $\mathrm{p}=$ pith, $\mathrm{np}=$ nonfunctioning phloem, ve $=$ vessel elements.

Table 2. Vessel frequency per cross-sectional area 6 months after budgrafting sweet cherry scion-rootstock combinations (2001). Sections of ungrafted rootstock were taken at the approximate height as in grafted combinations. Rootstocks included were 'Gisela 5' (Gi 5), 'Gisela 6' (Gi6), and 'Colt' with 'Rainier' as scion tissue in heterograft combinations. These samples were uniform throughout the stem and all data were pooled in ungrafted samples. Statistical differences are shown for overall treatments, with no significant differences detected among sections.

\begin{tabular}{|c|c|c|}
\hline \multicolumn{2}{|c|}{ Treatment } & $\begin{array}{l}\text { Mean vessel frequency } \pm \text { SE } \\
\qquad\left(\mathrm{mm}^{2}\right)^{\mathrm{z}}\end{array}$ \\
\hline \multirow[t]{3}{*}{ Ungrafted } & Gi 5 & $43.4 \pm 4.2 \mathrm{~b}$ \\
\hline & Gi 6 & $52.1 \pm 11.3 \mathrm{a}$ \\
\hline & Colt & $35.6 \pm 4.4 \mathrm{c}$ \\
\hline \multicolumn{3}{|l|}{ Homografts } \\
\hline \multirow[t]{3}{*}{ Gi 5/Gi 5} & Scion & $32.5 \pm 3.4$ \\
\hline & Graft union & $30.9 \pm 5.3 \mathrm{~cd}$ \\
\hline & Rootstock & $24.0 \pm 2.9$ \\
\hline \multirow[t]{3}{*}{ Gi 6/Gi 6} & Scion & $30.9 \pm 2.4$ \\
\hline & Graft union & $34.0 \pm 6.6 \mathrm{c}$ \\
\hline & Rootstock & $38.3 \pm 6.7$ \\
\hline \multirow[t]{3}{*}{ Colt/Colt } & Scion & $25.0 \pm 3.5$ \\
\hline & Graft union & $27.5 \pm 4.2 \mathrm{~d}$ \\
\hline & Rootstock & $22.5 \pm 1.4$ \\
\hline \multicolumn{3}{|l|}{ Heterografts } \\
\hline \multirow[t]{3}{*}{ Rainier/Gi 5} & Scion & $33.7 \pm 4.0$ \\
\hline & Graft union & $31.9 \pm 5.3 \mathrm{~cd}$ \\
\hline & Rootstock & $32.4 \pm 4.5$ \\
\hline \multirow[t]{3}{*}{ Rainier/Gi 6} & Scion & $37.4 \pm 4.5$ \\
\hline & Graft union & $27.2 \pm 3.8 \mathrm{~cd}$ \\
\hline & Rootstock & $31.5 \pm 5.2$ \\
\hline \multirow[t]{3}{*}{ Rainier/Colt } & Scion & $28.2 \pm 4.5 \mathrm{~d}$ \\
\hline & Graft union & $24.3 \pm 2.9$ \\
\hline & Rootstock & $26.4 \pm 4.5$ \\
\hline
\end{tabular}

$\overline{\mathrm{Z}}$ Letters denote differences in mean separation within a column by LSD at $P \leq 0.05$.
Interestingly, homografts of 'Gi 5' and 'Gi 6' had greater number of vessel elements in graft union tissues than 'Colt' (Table 2). 'Gi 5'/'Gi 5' had the highest $\mathrm{VD}_{\mathrm{h}}$ in scion tissues of homograft combinations including ${ }^{\circ} \mathrm{F}$ $12 / 1^{\prime}$ ' Table 4). This suggests that although there is an impact from wounding, 'Gi 5' or ' Gi6' homografts have a different growth response when grafted to genetically identical rootstock. The difference in response for altered sweet cherry graft combinations was verified in 2002, when 'Gi 5' and 'Gi 6' reciprocal grafts yielded greater $\mathrm{VD}_{\mathrm{h}}$ than their respective hetero - and homografts (i.e., $\mathrm{LAV}={ }^{\prime} \mathrm{Gi} 6{ }^{\prime} /{ }^{\circ} \mathrm{F} 12 / 1$ ' > 'Gi 5'/'F 12/1'> 'Rainer'/'F 12/1'). Collectively, these relationships suggest a wider range in growth responses than can be accounted for by impact of wound-related callus formation alone.

Grafting inverted 'Macintosh' apple bark rings onto the same scion wood produced greater differentiation of callus into phloem cells than xylem cells, with initial differentiation occurring at the basipetal portion of the graft union (Poniedzialek et al., 1979). In apple, not only was there a reduction in the xylem : phloem ratio, but xylem cell diameter and number decreased progressively in the basipetal portion of the graft union. The reduction in numbers of xylem cells differentiated during the healing of a graft wound suggests a specific physiological response associated with grafting that could be exacerbated when dwarfing rootstocks are used in graft combinations, because dwarfing rootstocks are predisposed to fewer and smaller xylem elements under those conditions.

In these experiments there was an added effect of rootstock dwarfing potential on vessel size and number in heterograft combinations. Dwarfing combinations tended to produce a greater number of small vessels with reduced calculated hydraulic conductance. Lumen area per vessel was smaller in graft union of ' $G i$ ' 5 ' heterograft combinations, indicating that a hydraulic restriction may occur in the graft union of genetically mixed tissue (scion + rootstock). Thus, 2001 values for $\mathrm{VD}_{\mathrm{h}}$ would support the hypothesis that 'Rainier'/'Gi 5' graft union tissue may have lower hydraulic conductivity than scion or rootstock tissues. In addition, the number of vessels was less in 'Gi 5' than in semidwarfing and nondwarfing rootstocks. Collectively, this suggests that in the 'Gi 5' rootstock combinations, a greater proportion of the reduced vessel elements were composed of narrow vessels.

Rootstock affected the structure and production of other vascular components, namely xylem rays and nonfunctional phloem. The presence of vascular anomalies in the graft union may further explain reductions in water transport between genetically different rootstock and scion (Simons and Chu, 1980). Parenchyma and xylem rays on an acute angle to the longitudinal axis of the tree were prevalent in the dwarfing combination of 'Rainier'/ 'Gi 5' in comparison to 'Rainier'/“F 12/1'. The development of vessels in the graft union at acute angles to the existing vascular system may impede water and other transport. Preliminary research indicates there is a reduction in dye uptake through functional xylem vessels of the graft union in scion-rootstock combinations containing ' $\mathrm{Gi}$ 5 '(Olmstead et al., 2006). In addition to these vascular anomalies, there was an increased production of nonfunctioning phloem in 'Rainier'/'Gi 5' compared with 'Rainier'/‘F 12/1' (Fig. 4C-D), which substantiates a similar response observed earlier in apple of an increased phloem to xylem ratio in dwarfing rootstocks and the graft union (Beakbane and Thompson, 1939, 1947; Sommeli- 
Table 3. Maximum vessel diameter $\left(\mathrm{VD}_{\max }\right)$, mean vessel hydraulic diameter $\left(\mathrm{VD}_{\mathrm{h}}\right)$, and total number of vessels measured 6 months after bud-grafting sweet cherry scion-rootstock combinations in 2001. Sections of ungrafted rootstock were taken at the approximate height as in grafted combinations. Rootstocks included were 'Gisela 5' (Gi 5), 'Gisela 6' (Gi 6), and 'Colt' with 'Rainier' as scion tissue in heterograft combinations.

\begin{tabular}{|c|c|c|c|c|}
\hline \multicolumn{2}{|c|}{ Treatment } & \multirow{2}{*}{$\begin{array}{c}\mathrm{VD}_{\max }(\mu \mathrm{m}) \\
24.5\end{array}$} & \multirow{2}{*}{$\frac{\mathrm{VD}_{\mathrm{h}}(\mu \mathrm{m})^{\mathrm{z}}}{16.6 \mathrm{c}-\mathrm{e}}$} & \multirow{2}{*}{$\frac{n}{29}$} \\
\hline Ungrafted & Gi 5 & & & \\
\hline & Gi 6 & 27.3 & $20.7 \mathrm{a}$ & 16 \\
\hline & Colt & 26.6 & $19.1 \mathrm{ab}$ & 25 \\
\hline \multicolumn{5}{|l|}{ Homografts } \\
\hline \multirow[t]{3}{*}{ Gi 5/Gi 5} & Scion & 18.4 & $13.6 \mathrm{~g}$ & 20 \\
\hline & Graft union & 26.1 & $15.8 \mathrm{~d}-\mathrm{f}$ & 46 \\
\hline & Rootstock & 21.8 & 15.1 ef & 10 \\
\hline \multirow[t]{3}{*}{ Gi 6/Gi 6} & Scion & 23.6 & $15.8 \mathrm{c}-\mathrm{f}$ & 20 \\
\hline & Graft union & 26.2 & 17.2 b-e & 54 \\
\hline & Rootstock & 24.4 & $18.9 \mathrm{ab}$ & 28 \\
\hline \multirow[t]{3}{*}{ Colt/Colt } & Scion & 24.9 & $15.8 \mathrm{c}-\mathrm{f}$ & 16 \\
\hline & Graft union & 29.7 & 15.3 ef & 54 \\
\hline & Rootstock & 28.5 & $18.5 \mathrm{a}-\mathrm{c}$ & 12 \\
\hline \multicolumn{5}{|l|}{ Heterografts } \\
\hline \multirow[t]{3}{*}{ Rainier/Gi 5} & Scion & 23.5 & $16.6 \mathrm{c}-\mathrm{e}$ & 24 \\
\hline & Graft union & 22.4 & $13.9 \mathrm{~g}$ & 50 \\
\hline & Rootstock & 25.1 & $17.2 \mathrm{~b}-\mathrm{e}$ & 16 \\
\hline \multirow[t]{3}{*}{ Rainier/Gi 6} & Scion & 28.3 & $19.2 \mathrm{ab}$ & 18 \\
\hline & Graft union & 30.8 & $17.4 \mathrm{~b}-\mathrm{d}$ & 54 \\
\hline & Rootstock & 26.0 & $18.9 \mathrm{a}-\mathrm{c}$ & 12 \\
\hline \multirow[t]{3}{*}{ Rainier/Colt } & Scion & 28.5 & $16.4 \mathrm{c}-\mathrm{f}$ & 16 \\
\hline & Graft union & 31.4 & $16.5 \mathrm{c}-\mathrm{e}$ & 40 \\
\hline & Rootstock & 20.3 & $15.6 \mathrm{~d}-\mathrm{f}$ & 10 \\
\hline
\end{tabular}

${ }^{\mathrm{Z}}$ Letters denote differences in mean separation within a column by LSD at $P \leq 0.05$.

dou et al., 1994b). Such anomalies could directly affect transport and thus have an additive impact on tree growth by contributing to the previously reported increases in hydraulic resistance and reductions in shoot growth in dwarfing rootstocks (Atkinson et al., 2003; Basile et al., 2003).

Although 'Gi 5' and 'Gi 6' are of the same genetic background, this work shows that they can affect growth and development differently, and corroborates previous reports of differences in sweet cherry scion growth on these two rootstocks (Perry et al., 1997). Alterations in the transport of water and nutrients can have a profound impact on plant growth. However, the transport of important chemical messengers could also be influenced by a restriction in xylem and phloem transport. Based on previous studies with dwarfing rootstocks (Soumelidou et al., 1994a), it is possible that changes in auxin concentration are more pronounced in 'Gi 5' tissue. Reduced vessel sizes and subsequent reductions in vessel length were achieved by partially girdling stems in Acer rubrum L. (Aloni and Zimmerman, 1984). It was speculated that perhaps this could be due to changes in auxin concentration at the girdling site that reduced diameter and length in developing vessels in response to wounding.

As in many plant systems, it is likely that a number of processes affect growth in grafted cherry trees. We submit that the combination of a larger proportion of narrow vessels with lower theoretical hydraulic conductance and increased incidences of vascular anomalies may greatly contribute to the dwarfed scion habit when ' $\mathrm{Gi} 5$ ' is used as rootstock in a grafted cherry tree.
Table 4. Maximum vessel diameter $\left(\mathrm{VD}_{\max }\right)$, vessel hydraulic diameter $\left(\mathrm{VD}_{\mathrm{h}}\right)$, total number of vessels measured $(\mathrm{n})$, and number of replicate samples measured for each treatment (N) in 2002. Vessels were measured from the pith to the vascular cambium. Ungrafted rootstocks were used as controls, and samples were collected at the approximate height as in grafted combinations. Rootstocks included were 'Gisela 5' (Gi 5), 'Gisela 6' (Gi 6), and 'F 12/1' with 'Rainier' as scion tissue in heterograft combinations.

\begin{tabular}{cccccc}
\hline \multicolumn{2}{c}{ Treatment } & $\mathrm{VD}_{\max }(\mu \mathrm{m})$ & $\mathrm{VD}_{\mathrm{h}}(\mu \mathrm{m})^{\mathrm{z}}$ & $\mathrm{n}$ & $\mathrm{N}$ \\
\hline Ungrafted & Gi 5 & 51.6 & $27.6 \mathrm{j}$ & 288 & 3 \\
& $\mathrm{Gi} \mathrm{6}$ & 79.8 & $26.9 \mathrm{k}$ & 242 & 3 \\
& $\mathrm{~F} \mathrm{12/1}$ & 56.2 & $33.3 \mathrm{a}$ & 240 & 3 \\
\hline Homografts & & & & & \\
Gi 5/Gi 5 & Scion & 47.5 & $24.3 \mathrm{l}$ & 144 & 3 \\
& Graft union & 46.6 & $28.1 \mathrm{ij}$ & 286 & 5 \\
& Rootstock & 55.3 & $30.9 \mathrm{c}$ & 494 & 5 \\
Gi 6/Gi 6 & Scion & 31.0 & $17.6 \mathrm{~m}$ & 128 & 2 \\
& Graft union & 54.7 & $29.7 \mathrm{~d}-\mathrm{f}$ & 240 & 6 \\
Rainier/F 12/1 & Rootstock & 37.5 & $30.3 \mathrm{~cd}$ & 450 & 6 \\
& Scion & 42.9 & $16.0 \mathrm{~m}$ & 72 & 2 \\
& Graft union & 27.2 & $28.2 \mathrm{~h}-\mathrm{j}$ & 142 & 3 \\
& Rootstock & 28.0 & $32.9 \mathrm{ab}$ & 234 & 3 \\
\hline Heterografts & & & & & \\
Rainier/Gi 5 & Scion & 14.0 & $6.6 \mathrm{n}$ & 166 & 2 \\
& Graft union & 24.0 & $29.5 \mathrm{e}-\mathrm{g}$ & 320 & 4 \\
& Rootstock & 26.4 & $29.7 \mathrm{de}$ & 280 & 4 \\
Rainier/Gi 6 & Graft union & 50.3 & $30.1 \mathrm{c}-\mathrm{e}$ & 364 & 6 \\
& Rootstock & 53.5 & $29.0 \mathrm{f}-\mathrm{h}$ & 546 & 6
\end{tabular}

Reciprocal

heterografts

Gi 5/F 12/1

$\begin{array}{cc}\text { Scion } & 45.3 \\ \text { Graft union } & 59.9 \\ \text { Rootstock } & 66.9 \\ \text { Scion } & 53.8 \\ \text { Graft union } & 55.9 \\ \text { Rootstock } & 53.3\end{array}$

$\begin{array}{lll}27.5 \mathrm{jk} & 206 & 3 \\ 28.7 \mathrm{~g}-\mathrm{i} & 200 & 4 \\ 32.1 \mathrm{~b} & 358 & 4 \\ 23.31 & 156 & 3 \\ 26.9 \mathrm{jk} & 282 & 4 \\ 31.9 \mathrm{~b} & 236 & 4\end{array}$

$\overline{\mathrm{z}}$ Letters denote differences in mean separation within a column by LSD at $P \leq 0.05$.

\section{Literature Cited}

Aloni, R. and M.H. Zimmerman. 1984. Length, width, and pattern of regenerative vessels along strips of vascular tissue. Bot. Gaz. 145:50-54.

Atkinson, C.J., M.A. Else, L. Taylor, A.D. Webster. 2001. The rootstock graft union: A contribution to the hydraulics of the worked fruit tree. Acta Hort. 557:117-122.

Atkinson, C.J., M.A. Else, L. Taylor, C.J. Dover. 2003. Root and stem hydraulic conductivity as determinants of growth potential in grafted trees of apple (Malus pumila Mill.). J. Expt. Bot. 54:1221-1229.

Basile, B., J. Marsal, and T.M. DeJong. 2003. Daily shoot extension growth of peach trees growing on rootstocks that reduce scion growth is related to daily dynamics of stem water potential. Tree Physiol. 23:695-704.

Beakbane, A.B. and E.C. Thompson. 1939. Anatomical studies of stems and roots of hardy fruit trees. II. The internal structure of the roots of some vigorous and some dwarfing apple rootstocks, and the correlation of structure with vigour. J. Hort. Sci. 17:141-149.

Beakbane, A.B. and E.C. Thompson. 1947. Anatomical studies of stems and roots of hardy fruit trees. IV. The root structure of some new clonal apple rootstocks budded with Cox's Orange Pippen. J. Hort. Sci. 23:206-211.

Flegler, S.L., J.W. Heckman, Jr., and K.L. Klomparens. 1993. Specimen Preparation for SEM, p. 160-161. In: S.L. Flegler, J.W. Heckman, 


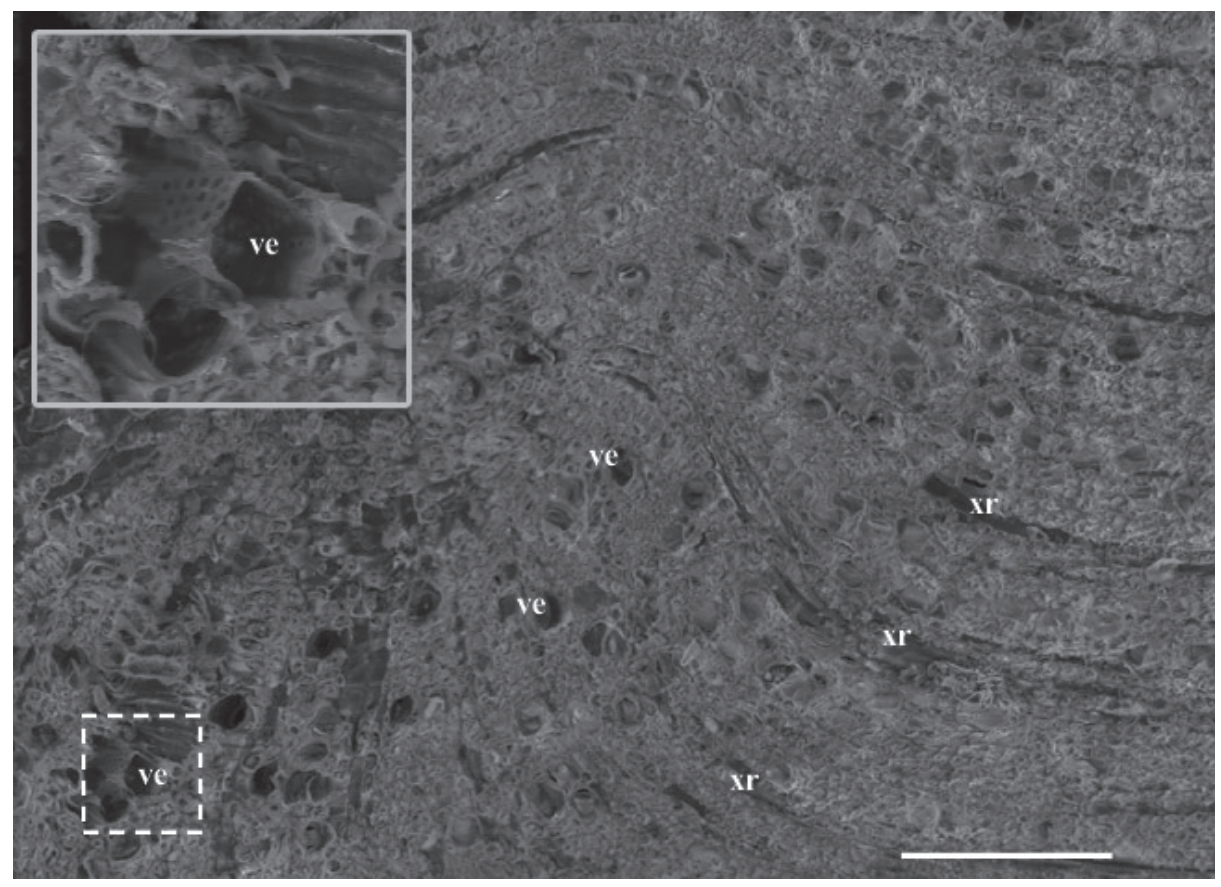

Fig. 5. Vascular anomalies perpendicular to the tree longitudinal axis in graft union tissue of an interspecific heterograft of sweet cherry ('Rainier'/'Gisela 5') included whorls of vascular tissue and vessels at an acute angle (inset); ve $=$ vessel element, $\mathrm{xr}=$ xylem ray.

Jr., and K.L. Klomparens (eds.). Scanning and transmission electron microscopy. Oxford Univ. Press, New York.

Gur, A., R.M. Samish, and E. Lifshitz. 1968. The role of the cyanogenic glycoside of the quince in the incompatibility between pear cultivars and quince rootstocks. Hort. Res. 8:113-134.

Gur, A. and A. Blum. 1975. The water conductivity of defective graft unions in pome and stone fruits. J. Amer. Soc. Hort. Sci. 100:325328.

Jones, O.P. 1974. Xylem sap composition in apple trees: Effect of the graft union. Ann. Bot. 38:463-467.

Jones, O.P. 1986. Endogenous growth regulators and rootstock/scion interactions in apple and cherry trees. Acta Hort. 179:177-183.

Kamboj, J.S., G. Browning, J.D. Quinlan, P.S. Blake, and D.A. Baker. 1997. Polar transport of [ $\left.{ }^{3} \mathrm{H}\right]-$ IAA in apical shoot segments of different apple rootstocks. J. Hort. Sci. 72: 773-780.

Kamboj, J.S., P.S. Blake, J.D. Quinlan, and D.A. Baker. 1999. Identification and quantitation by GC-MS of zeatin and zeatin riboside in xylem sap from rootstock and scion of grafted apple trees. Plant Growth Regulat. 28:199-205.

Lillie, R.D. 1977. H.J. Conn's biological stains, p. 385-387. 9th ed. Williams and Wilkins Co., Baltimore, Md.

McKenzie, D.W. 1961. Rootstock-scion interaction in apples with special reference to root anatomy. J. Hort. Sci. 36:40-47.

Nobel, P.S. 1999. Physiochemical and environmental plant physiology. p. 375-378. 2nd ed. Academic, San Diego, Calif.

Olmstead, M.A., N.S. Lang, G.A. Lang, F.W. Ewers, and S.A. Owens. 2006. Examining the vascular pathway of sweet cherries grafted onto dwarfing rootstocks. HortScience 41:674-679.
Perry, R., G.Lang, R. Anderson, L. Anderson, A. Azarenko, T. Facteau, D. Ferree,A. Gaus, F. Kappel, F. Morrison, C. Rom, T. Roper, S. Southwick, G. Tehrani, and C. Walsh. 1997. Performance of the NC-140 cherry rootstock trials in North America. Acta Hort. 451:225-229.

Poniedzialek, W., W. Lech, and M. Urbanek. 1979. Anatomical changes in the grafted apple bark rings. Fruit Sci. Rpt. 6:115-133.

Pockman, W.T. and J.S. Sperry. 2000. Vulnerability to xylem cavitation and the distribution of Sonoran Desert vegetation. Amer. J. Bot. 87:1287-1299.

Ruzin, S.E. 1999. Plant microtechnique and microscopy. Oxford Univ. Press, New York.

Simons, R.K. and M.C. Chu. 1980. Graft union patterns in M.26 and other apple rootstocks. Compact Fruit Tree 13:42-47.

Soumelidou, K., D.A. Morris, N.H. Battey, J.R. Barnett, and P. John. 1994a. Auxin transport capacity in relation to the dwarfing effect of apple rootstocks. J. Hort. Sci. 69:719-725.

Soumelidou, K., N.H. Battey, J.R. Barnett, and P. John. 1994b. The anatomy of the developing bud union and its relationship to dwarfing in apple. Ann. Bot. 74:605-611.

Steedman, H.F. 1960. Section Cutting in Microscopy. CC Thomas, Springfield, Ill.

Tyree, M.T. and F.W. Ewers. 1991. The hydraulic architecture of trees and other woody plants. New Phytol. 119:345-360.

Tyree, M.T. and M.H. Zimmerman. 2002. Xylem structure and the ascent of sap. Springer, Berlin.

Zimmerman, M.H. and A.A. Jeje. 1981. Vessel-length distribution in stems of some American woody plants. Can. J. Bot. 59:18821892. 